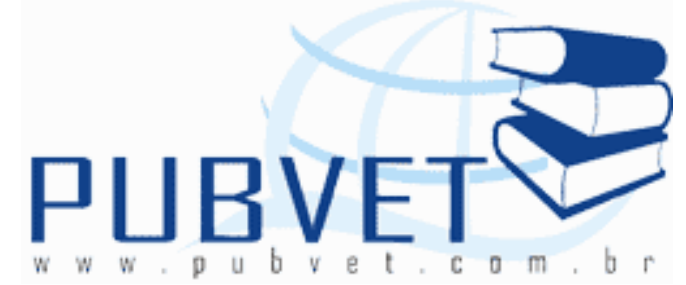

PUBVET, Publicações em Medicina Veterinária e Zootecnia.

\title{
Seleção assistida: proposta de otimização utilizando Algoritmos Genéticos
}

Natanael Pereira da Silva Santos ${ }^{1}$, José Lindenberg Rocha Sarmento ${ }^{2}$, José Elivalto Guimarães Campelo ${ }^{3}$, Aurino de Araujo Rego Neto ${ }^{4}$, Vanessa dos Santos Neri ${ }^{5}$, Tatiana Saraiva Torres ${ }^{5}$

${ }^{1}$ Aluno de Doutorado do Programa de Pós-Graduação em Ciência Animal da UFPI. Teresina-PI. E-mail: natanaelpss@hotmail.com

${ }^{2}$ Professor, Doutor do Campus Cinobelina Elvas, Bom Jesus - UFPI

${ }^{3}$ Professor, Doutor do Campus Petrônio Portela, Teresina - UFPI.

${ }^{4}$ Discente do Programa de Pós-Graduação em Ciência Animal da UFPI, Teresina ${ }^{5}$ Discentes do curso Bacharelado em Zootecnia da UFPI, Bom Jesus - PI

\section{Resumo}

O avanço da computação e da informatização tem influenciado os procedimentos de avaliação genética, permitindo, com isso, comparações de méritos genéticos dos animais entre rebanhos, raças ou países. O fenômeno da convergência de tecnologias deixa explicita a importância dos sistemas de informações gerenciais frente a manipulação da enorme quantidade de dados oriundos de vários tipos de integrações na busca de melhores respostas. Em função disso, neste artigo são apresentadas e discutidas algumas tendências e aplicações de algoritmos evolucionários focando-se a otimização da seleção de animais para acasalamentos assistidos no melhoramento animal. Este trabalho 
caracteriza-se como um ensaio teórico realizado a partir de revisão bibliográfica.

Palavras-chave: algoritmo genético, melhoramento genético, otimização, seleção assistida

\title{
Assisted selection: proposal optimization using Genetic Algorithms
}

\begin{abstract}
Advances in computing and information technology has influenced the genetic evaluation procedures, allowing thereby, comparisons of genetic merit of animals between herds, races or countries. The phenomenon of convergence of technologies makes explicit the importance of management information systems against manipulation of large amounts of data from various types of integrations in the search for better answers. As a result, in this article are presented and discussed some trends and applications of evolutionary algorithms focusing on optimizing the selection of animals for assisted mating in animal breeding. This work is characterized as a theoretical test conducted based on literature review.
\end{abstract}

Keywords: genetic algorithm, genetic improvement, optimization, assisted selection

\section{Introdução}

Acompanhando a demanda por produtos de qualidade, crescem também as cobranças por melhores condições de criação o que requer dos criadores uma mudança na maneira de produzir. Ante esse cenário, criadores e produtores de animais de interesse econômico precisam melhorar o potencial genético de seus rebanhos para atender, a médio e longo prazo, os anseios do mercado por melhores produtos. Isso inclui a necessidade da utilização de reprodutores e matrizes com potencial genético capaz de produzir progênies que atendam as maiores exigências. 
SANTOS, N.P.S. et al. Seleção assistida: proposta de otimização utilizando Algoritmos Genéticos. PUBVET, Londrina, V. 6, N. 19, Ed. 206, Art. 1378, 2012.

Dessa forma, uma possível maneira de resolver questões ligadas ao melhoramento desses animais seria seguir um conjunto de regras recomendadas por geneticistas e profissionais liberais. No entanto, tais regras são derivadas de teorias e conceitos generalizados, e normalmente, não são bem integradas umas com as outras. Por exemplo, teorias e regras sobre seleção, cruzamento e endogamia têm sido desenvolvidas amplamente, porém isoladas umas das outras, o que torna difícil envolvê-las de maneira integrada em aplicações reais, excluindo a que seria, provavelmente, a melhor estratégia de ação por parte do produtor.

O avanço da computação e da informatização tem influenciado os procedimentos de avaliação genética, permitindo, com isso, comparações de méritos genéticos dos animais entre rebanhos, raças ou países. Destaca-se que a adoção de técnicas aplicadas ao melhoramento depende do equilíbrio entre o que é possível, sob o ponto de vista tecnológico, e o que é aceitável, no contexto socioeconômico de um sistema de produção.

Diante do desafio de maximizar o melhor arranjo dessas teorias de forma integrada surgem os Algoritmos Genéticos (AGs), inspirados no processo de evolução natural, que buscam a melhor solução para os problemas de otimização, utilizando um processo iterativo de busca da melhor solução para o problema (COSTA, 2009). Estes algoritmos fazem parte de uma família de modelos computacionais que simulam processos naturais aplicado a soluções de problemas reais de bioinformática, como por exemplo, a descoberta da estrutura de RNA (FOGEL et al., 2002) e para a predição de "non-coding" RNA (ncRNA) (SATROM et al., 2005).

O fenômeno da convergência de tecnologias deixa explicita a importância dos sistemas de informações gerenciais frente a manipulação da enorme quantidade de dados oriundos de vários tipos de integrações na busca de melhores respostas. Em função disso, neste artigo são apresentadas e discutidas algumas tendências e aplicações de Algoritmos Evolucionários focando-se a otimização da seleção de animais para acasalamentos assistidos 
SANTOS, N.P.S. et al. Seleção assistida: proposta de otimização utilizando Algoritmos Genéticos. PUBVET, Londrina, V. 6, N. 19, Ed. 206, Art. 1378, 2012.

no melhoramento animal. Este trabalho caracteriza-se como um ensaio teórico realizado a partir de revisão bibliográfica.

\section{Estratégias de seleção para programas de melhoramento}

A taxa reprodutiva e a incerteza relativa ao mérito genético real dos animais são fatores mais limitantes dos programas de melhoramento. Esses fatores podem ser os determinantes de quantos e quais animais devem ser selecionados. Com isso, os investimentos dos programas estão, muitas vezes, relacionados com a mensuração de características, avaliação genética e técnicas para aumentar os índices reprodutivos (CARDOSO et al., 2003).

Registros de produção (medidas fenotípicas) em quantidade e com qualidade possibilitam identificar de modo mais adequado os animais geneticamente superiores, resultando numa seleção mais acurada e, em consequência, na obtenção de maiores ganhos genéticos.

Dada a circunstância dos recursos serem escassos, como alternativa, pode-se avaliar as características de um grupo limitado de animais, criando-se um grupo de elite ou núcleo de animais mais prováveis de serem escolhidos como futuros reprodutores. Outra opção seria a realização de testes de progênies, o que aumentaria a acurácia de seleção dos machos, especialmente para características de baixa herdabilidade e/ou limitadas pelo sexo (SILVA, 2010).

O uso de técnicas reprodutivas pode ser mais uma alternativa de investimento, visto que, os fatores mais importantes que determinam o ganho genético são direcionados pela taxa reprodutiva dos animais. Este fato tornase evidente por que índices reprodutivos mais altos permitem a retenção de um número menor de reprodutores, aumentando, portanto, a intensidade de seleção desses animais (NEVES et al., 2010).

A utilização de uma técnica reprodutiva como a inseminação artificial, por exemplo, envolve custos e seu benefício pode ser avaliado em termos do aumento na taxa de progresso genético ocasionado por sua adoção, pois, mais 
SANTOS, N.P.S. et al. Seleção assistida: proposta de otimização utilizando Algoritmos Genéticos. PUBVET, Londrina, V. 6, N. 19, Ed. 206, Art. 1378, 2012.

descendentes por animal resultam também em estimativas mais acuradas dos valores genéticos.

As técnicas reprodutivas permitem o uso intensivo de animais superiores, sendo que uma consequência óbvia disso é que, possivelmente, os animais mais conhecidos serão excessivamente usados, o que pode resultar em problemas de endogamia na população. Com a aplicação de novas técnicas de melhoramento animal pode-se obter mudanças genéticas mais intensas e rápidas, por isso questões de médio e longo prazo, como controle da endogamia e manutenção da variação genética tornam-se a cada dia mais importantes. Razão pela qual, nos últimos anos, as ferramentas de seleção vêm se tornando mais sofisticadas (BORGES et al., 2004).

Diante disso, a seleção ideal será realizada se diferentes fontes de informação forem combinadas e ponderadas adequadamente. Dentre os métodos que tem a capacidade de combinar e ponderar adequadamente essas diferentes fontes de informação destaca-se o Melhor Preditor Linear NãoViesado (BLUP).

No entanto, os métodos que procuram reproduzir os efeitos biológicos possuem erro de predição, e com o BLUP otimizar a seleção a longo prazo, parece ser vantajosa somente quando dada pela combinação da seleção baseada nos valores genéticos com alguma restrição na média de parentesco dos animais selecionados. No entanto, essa prática pode ser erroneamente empregada quando realizada sem critérios e controles específicos. Assim, alternativas que visem otimização desses fatores de forma integrada, considerando várias restrições e baseadas em conceitos biológicos, podem melhorar as predições futuras.

\section{Avaliação genética e Seleção}

Em situações reais, no melhoramento animal, ao se definir uma estratégia de seleção visando maiores respostas genéticas, no menor intervalo de tempo, fatores relevantes como: os tamanhos real e efetivo da população, a 
SANTOS, N.P.S. et al. Seleção assistida: proposta de otimização utilizando Algoritmos Genéticos. PUBVET, Londrina, V. 6, N. 19, Ed. 206, Art. 1378, 2012.

intensidade e a acurácia da seleção, o método de seleção utilizado, o tempo total de seleção, os sistemas de acasalamentos praticados, além do conhecimento da própria característica considerada na seleção, são fundamentais. Na maioria das vezes estes fatores relacionam-se, e, não raramente, há entre eles relações antagônicas (MUIR, 1997; CUNHA et al., 2003), que dificultam a otimização do processo de seleção.

No processo de coleta dos dados, as performances individuais precisam ser relacionadas à identificação do animal. Caso o BLUP seja usado para gerar as Diferenças Esperadas de Progênie (DEPs), é necessário conhecer o pedigree dos animais. Caso a informação de parentesco não seja considerada, o valor genético será determinado somente pelo próprio desempenho e será limitado ao sexo que expressa as características de interesse (KINGHORN et al., 2006).

A seleção com base nas soluções de modelos mistos (BLUP dos valores genéticos) maximiza a resposta à seleção. No entanto, a resposta somente é maximizada com relação à próxima geração. A resposta à seleção a longo prazo não é necessariamente otimizada em virtude da seleção com base no BLUP levar a uma maior endogamia do que, por exemplo, a seleção massal (baseada no próprio fenótipo). Consequentemente, a longo prazo, uma maior endogamia leva a perda de variação genética e, possivelmente, haverá depressão endogâmica e redução do ganho genético (QUEIROZ et al., 2000; CUNHA et al, 2003).

\section{Acasalamento}

Decisões sobre quais animais devem ser acasalados, frequentemente, são vistas sobre a ótica de cruzamentos ou relacionadas a efeitos de dominância. A utilização da variação de dominância, no geral, não é primordial para o melhoramento de raças puras, podendo ter maior impacto em animais cruzados, nos quais os efeitos heteróticos entre raças podem ser mais explorados (PEREIRA, 2008; BARBOSA NETO et al., 2010). 
SANTOS, N.P.S. et al. Seleção assistida: proposta de otimização utilizando Algoritmos Genéticos. PUBVET, Londrina, V. 6, N. 19, Ed. 206, Art. 1378, 2012.

Quando mais de uma característica está envolvida no objetivo final, acasalamentos dirigidos podem ser vantajosos, combinando as diferentes qualidades dos pais para as distintas características. Há grande possibilidade de que um futuro próximo, quando efeitos de genótipos específicos forem mais bem compreendidos, os acasalamentos planejamentos ou dirigidos assumam maior importância. Com isso, será possível imaginar, por exemplo, a combinação de certos genótipos de alto potencial de crescimento com genes específicos de efeito maior sobre a qualidade de determinado produto (KINGHORN et al., 2006).

Outro argumento para o uso de acasalamentos dirigidos está relacionado com a possibilidade de evitar a endogamia na descendência direta, assim como o grau de endogamia na população (BORGES et al., 2004). No entanto, o grau de endogamia depende também do tamanho da população e do número de pais selecionados (QUEIROZ et al., 2000; BREDA et al., 2004).

Diante disso, Cavalheiro et al. (2010), sugerem que direcionar os acasalamentos sem comprometer o mérito predito da progênie e, inclusive, a combinação de acasalamento com restrição sobre endogamia pode proporcionar maior progresso genético que o acasalamento aleatório.

\section{Otimizando os componentes de ganhos genéticos}

Opções alternativas, para o progresso genético, precisam ser bem julgadas e avaliadas, o que pode ser feito pela análise dos componentes mais importantes que determinam a taxa de ganho genético, dentre eles: a intensidade de seleção, a acurácia de seleção e o intervalo de gerações. É importante salientar que pode haver interações entre tais componentes.

De acordo com Kinghorn et al. (2006), a seleção de animais jovens não resultará apenas em intervalos de gerações pequenos, mas poderá também implicar em baixa acurácia de seleção, porque os animais jovens têm geralmente menos informações disponíveis (por falta de medidas repetidas, da própria performance, ou de teste de progênie). Esses autores ainda 
mencionam que se mais animais jovens são selecionados como reprodutores e uma alta taxa de reposição é aplicada, o intervalo de gerações pode ser reduzido, mas a intensidade de seleção também será baixa, uma vez que mais animais da nova geração serão usados na reposição.

Fica evidente que alternativas podem ser utilizadas como estratégias de otimização da relação entre os diferentes componentes, dentre elas, para o exemplo acima, sugere-se o descarte de animais velhos e retenção de animais mais jovens, o que possibilitará decréscimo no intervalo de gerações compensando na intensidade de seleção, e o ganho genético anual será maximizado.

Nas condições reais de campo, onde é possível encontrar animais de diversas idades, a seleção baseada nas DEPs podem ser comparáveis entre classes de idade, então a melhor alternativa será simplesmente selecionar os melhores animais dentre todos os candidatos independentemente da idade. Quanto maior a taxa de progresso genético, mais animais jovens serão selecionados, dada a superioridade deles, devido à tendência genética. 0 intervalo de gerações ideal pode ser facilmente encontrado pela classificação dos animais de acordo com as DEPs (CARDOSO et al, 2003).

Portanto, os processos de otimização poderiam ser utilizados como alternativa para testar várias combinações e encontrar a melhor solução para o caso.

\section{Algoritmos Genéticos}

Os Algoritmos Genéticos são algoritmos de otimização global, baseados nos mecanismos de seleção natural e da genética (recombinação e mutação). Eles empregam uma estratégia de busca paralela e estruturada, mas aleatória, que é voltada em direção ao reforço da busca de pontos de 'alta aptidão', ou seja, pontos nos quais a função a ser minimizada (ou maximizada) tem valores relativamente baixos (ou altos) (LINDEN, 2006). 
SANTOS, N.P.S. et al. Seleção assistida: proposta de otimização utilizando Algoritmos Genéticos. PUBVET, Londrina, V. 6, N. 19, Ed. 206, Art. 1378, 2012.

Apesar de aleatórios, os AGs não são 'caminhadas' aleatórias não direcionadas, pois exploram informações históricas para encontrar novos pontos de busca onde são esperados melhores desempenhos. Isto é feito através de processos iterativos, onde cada iteração pode ser considerada uma nova geração.

Durante cada iteração, os princípios de seleção e reprodução são aplicados a uma população de candidatos que pode variar, dependendo da complexidade do problema e dos recursos computacionais disponíveis. Segundo Costa (2009), através da seleção, se determina quais indivíduos conseguirão se reproduzir, gerando um número determinado de descendentes para a próxima geração, com uma probabilidade determinada pelo seu índice de aptidão. Em outras palavras, os indivíduos com maior adaptação relativa têm maiores chances de se reproduzir.

Os AGs diferem dos métodos tradicionais de busca e otimização, principalmente por trabalharem com uma codificação do conjunto de parâmetros e não com os próprios parâmetros, bem como trabalham com toda população e não com um único ponto. Além disso, esses algoritmos utilizam regras de transição probabilísticas e não impõem muitas das limitações encontradas nos métodos de busca tradicionais. Assim sendo, os AGs com a mesma população inicial e o mesmo conjunto de parâmetros pode encontrar soluções diferentes a cada vez que é realizado o cruzamento entre os melhores (NAKAMURA et al., 2005).

O conceito de otimização, de qualquer tarefa ou processo, está diretamente ligado à sua realização do modo mais eficiente possível. Esta eficiência pode ser avaliada de inúmeras maneiras, conforme o tipo de tarefa a ser realizada. As tarefas de busca e otimização possuem vários componentes, entre eles: o espaço de busca, onde são consideradas todas as possibilidades de solução de um determinado problema e a função de avaliação. 


\section{Componentes dos Algoritmos Genéticos}

A configuração correta dos parâmetros de influência é, sem dúvida, um dos aspectos mais relevantes dentro da estratégia dos Algoritmos Genéticos. Não existe muita literatura sobre este tema, uma vez que tais configurações irão depender entre outras coisas da aplicação resolvida. Entretanto, é intuitivo que este passo seja de muita importância para um bom desempenho do mecanismo de busca, principalmente quando se trabalha com dados fenotípicos.

Avaliação da População

A avaliação da população é realizada pela função de aptidão, que deve indicar a 'qualidade' de cada indivíduo na população. Para problemas de otimização ela está intimamente ligada à função objetivo que se deseja alcançar.

Vale ressaltar que essa aptidão pode variar ao longo do processo evolutivo, de maneira dinâmica e estocástica, imprecisa e mesmo subjetiva. É preciso lembrar, entretanto, que a escolha da função de aptidão é para a maioria das aplicações a etapa crítica do processo, já que ela deverá ser avaliada para cada cromossomo (indivíduo) de cada população dentro do processo (GONDRO; KINGHORN. 2008).

Destaca-se que, com uma população pequena o desempenho pode cair, pois deste modo a população fornece uma pequena cobertura do espaço de busca do problema. Por outro lado, uma grande população geralmente fornece uma cobertura representativa do domínio do problema, além de prevenir convergências prematuras para soluções locais ao invés de globais (BANDYOPADHYAY; PAL, 2007).

Esquemas de Seleção

O processo de seleção baseia-se no princípio da 'sobrevivência dos melhores indivíduos', onde os cromossomos (indivíduos) com melhor aptidão 
SANTOS, N.P.S. et al. Seleção assistida: proposta de otimização utilizando Algoritmos Genéticos. PUBVET, Londrina, V. 6, N. 19, Ed. 206, Art. 1378, 2012.

ou adequabilidade recebem uma maior probabilidade de serem copiados para um novo conjunto denominado população temporária, de onde serão aleatoriamente escolhidos para reprodução. Em contrapartida, os indivíduos com baixa aptidão serão descartados da população conforme a pressão de seleção do esquema utilizado (GONDRO; KINGHORN. 2008).

Inúmeros esquemas de seleção já foram propostos e implementados na prática dos Algoritmos Genéticos, alguns não sendo biologicamente plausíveis. A descrição e implementação de muitos desses esquemas são encontradas em Blickle e Thiele (1995).

\section{Reprodução ou Cruzamento}

Nesta etapa, o algoritmo tenta criar novas e melhores soluções (indivíduos mais aptos), por meio de operadores genéticos.

O princípio básico dos operadores genéticos é transformar a população através de sucessivas gerações, para obter um resultado satisfatório no final do processo. Deste modo, eles são extremamente necessários para que a população se diversifique e mantenha as características de adaptação adquiridas pelas gerações anteriores. Bandyopadhyay e Pal (2007) descrevem os operadores:

a) Operadores de Recombinação: Ao cruzar pelo menos dois pais, uma ou mais novas soluções são criadas permutando-se a informação genética dos genitores em um ou mais pontos que também são selecionados aleatoriamente.

b) Operadores de Mutação: O operador de mutação é necessário para a introdução e manutenção da diversidade genética na população, alterando arbitrariamente um ou mais componentes de uma estrutura escolhida. Ele fornece meios para a introdução de novos elementos na população, assegurando que a probabilidade de se chegar a qualquer ponto do espaço de busca nunca seja zero, com o intuito de tentar contornar o problema de ótimos locais. Geralmente se utiliza uma taxa 
de mutação pequena (como na genética natural), pois é um operador genético secundário.

Destaca-se que, quanto maior for a probabilidade de ocorrência de cruzamentos, mais rapidamente novas estruturas serão introduzidas na população. Em contrapartida, se ela for muito alta, estruturas com boas aptidões poderão ser retiradas mais rapidamente da população, ocorrendo perda de estruturas de alta aptidão. Valores baixos podem ainda tornar a convergência do algoritmo muito lenta (GONDRO; KINGHORN. 2008).

Cuidado similar deve ser dado à probabilidade da ocorrência de mutações, pois esta é empregada para fornecer novas informações dentro das populações visando aumentar a diversidade populacional e possibilitar maior varredura do espaço de busca (NARCISO; LORENA, 2002).

\section{Otimização no Melhoramento Genético Animal}

A maioria dos métodos de seleção fenotípica é projetada para escolher preferencialmente indivíduos com maiores notas de aptidão, embora não exclusivamente, a fim de manter a diversidade da população.

Nesse sentido, Neves et al. (2009) analisaram o impacto de diferentes estratégias de acasalamento em uma única geração, mas sugeriram que outras simulações devem ser conduzidas para contrastar estratégias de acasalamento em situações de ciclos repetidos de seleção e acasalamento, com a simulação de diferentes gerações. Esses autores concluíram que estratégias alternativas de acasalamento são eficientes em elevar a proporção de animais geneticamente superiores e, ao mesmo tempo, reduzir a variabilidade da progênie, mediante a redução da proporção de animais inferiores.

Apesar do potencial do método dos AGs, ao que se constatou na literatura consultada, a viabilidade do uso na seleção de animais foi investigada em somente com uso de evolução diferencial (LEE et al., 2008; CAVALHEIRO et al., 2010; KINGHORN, 2011). As teorias e hipóteses de utilização da 
SANTOS, N.P.S. et al. Seleção assistida: proposta de otimização utilizando Algoritmos Genéticos. PUBVET, Londrina, V. 6, N. 19, Ed. 206, Art. 1378, 2012.

otimização para ajudar a seleção de animais, baseada no desempenho fenotípico, a longo prazo, encontram-se descritas em Kinghorn et al. (2006).

Em pesquisa, Cavalheiro et al. (2010) objetivaram desenvolver um programa baseado em evolução diferencial, fundamentada pela teoria dos algoritmos evolucionários, para determinar melhor as contribuições genéticas, validar e testar o seu desempenho utilizando conjuntos de dados simulados e reais e avaliar empiricamente as consequências da execução aplicando abordagens diferentes para seleção ideal em regimes com gerações sobrepostas.

Os autores supracitados concluíram que é possível usar a evolução diferencial como um método de otimização para realizar seleção de contribuição ideal e que o programa desenvolvido é computacionalmente eficiente e viável para aplicações práticas. Além disso, informaram que as consequências esperadas de usar o programa, em contraste com as tentativas empíricas para controlar a endogamia e/ou seleção baseada exclusivamente no BLUP, são para melhorar a resposta de seleção e controle mais eficaz da endogamia.

Após a definição da contribuição genética ótima, o próximo passo natural deveria ser definir os acasalamentos. Com base nesse pressuposto, Kinghorn (2011) implementou um algoritmo para a seleção de parceiros para acasalamento utilizando a evolução diferencial com adaptações, que podem ser encontradas em Kinghorn (2008). De acordo com esse autor, o método, denominado GroupFix, não quebra as restrições de agrupamento declarado além de permitir maior flexibilidade a análise melhorando a robustez nas operações de seleção dos parceiros em comparação a outros métodos de seleção.

Vale ressaltar que a técnica de evolução diferencial diferencia-se dos AGs principalmente por empregar um operador de mutação diferencial com a intenção de gerar perturbações nos indivíduos da população corrente que será comparada ao indivíduo corrente, fazendo, dessa forma, uma busca pelo espaço de soluções. No entanto, esse operador é inspirado em argumentos 
SANTOS, N.P.S. et al. Seleção assistida: proposta de otimização utilizando Algoritmos Genéticos. PUBVET, Londrina, V. 6, N. 19, Ed. 206, Art. 1378, 2012.

matemáticos e heurísticos. Assim, à medida que o algoritmo progride, a aplicação do operador de mutação diferencial aos pares de indivíduos da população corrente gera vetores diferenciais que conduzem a uma modificação da distribuição espacial da população de acordo com a função objetivo do problema (KINGHORN, 2008).

Isso demonstra que apesar deste método ser considerado um algoritmo evolutivo, o operador de mutação diferencial não possui nenhuma inspiração oriunda de um processo natural, mas é referenciado como tal, pelo fato do método conduzir a evolução da população de soluções candidatas.

\section{Considerações Finais}

Os Algoritmos Genéticos permitem aos melhoristas incluir no problema seus conhecimentos provenientes da prática e, ainda, fornecer aos modelos sua estrutura de valores e preferências pessoais e específicos, de forma que os resultados encontrados sejam mais condizentes com a realidade enfrentada no planejamento dos cruzamentos.

Pode-se argumentar que a maior importância da utilização desta metodologia consiste em aproximar os modelos analíticos implementados à realidade vivida pelos produtores, bem como dos processos biológicos.

Por fim, pretende-se deixar claro que o propósito principal deste trabalho constitui em oferecer linhas de pensamento que, provavelmente, funcionem como um recurso adicional na análise do processo de tomada de decisão da seleção assistida, a longo prazo, com o uso dos Algoritmos Genéticos.

\section{Referências Bibliográficas}

BANDYOPADHYAY, S.; PAL, S. K. Classification and learning using Genetic Algorithms: applications in bioinformatics and web intelligence. New York: Springer, 2007. 313p.

BARBOSA NETO, A. C.; OLIVEIRA, S. M. P.; FACÓ, O. et al. Efeito s genéticos aditivos e nãoaditivos em características de crescimento, reprodutivas e habilidade materna em ovinos das raças Santa Inês, Somalis Brasileira, Doper e Poll Dorset. Revista Brasileira de Zootecnia, v. 39, n. 9, p. 1943-1951, 2010. 
BLICKLE, T.; THIELE, L., A Comparison of Selection Schemes used in Genetic

Algorithms. Zurich: Computer Engineering and Communication Networks Lab (TIK) \& Swiss Federal Institute of Technology (ETH), 1995.

BORGES, M.; BORGES, G. S. N.; RIBEIRO, H. G. PROGENIE R: sistema de auxílio às decisões de seleção e acasalamento em programas de melhoramento genético. In: SIMPÓSIO DA SOCIEDADE BRASILEIRA DE MELHORAMENTO ANIMAL, 5, 2004, Pirassununga. Anais... Pirassununga: Sociedade Brasileira de Melhoramento Animal, 2004. [CD ROM].

BREDA, F. C.; EUCLYDES, R. F.; PEREIRA, C. S. et al. Endogamia e limites de seleção em populações selecionadas obtidas por simulação. Revista Brasileira de Zootecnia, v. 33, n. 6, p. 2017-2025, 2004.

CARDOSO, V.; ROSO, V. M.; SEVERO, J. L. P. et al. Formando lotes uniformes de reprodutores múltiplos e usando-os em acasalamentos dirigidos, em população Nelore. Revista Brasileira de Zootecnia, v. 32, n. 4, p 834-842, 2003.

CAVALHEIRO, R.; QUEIROZ, S. A.; KINGHORN, B. Optimum contribuition selection using differential evolution. Revista Brasileira de Zootecnia, v. 39, n. 7, p. 1429-1436, 2010.

COSTA, E. J. X. Inteligência Artificial aplicada à Zootecnia. Revista Brasileira de Zootecnia, v. 38, p. 390-396, 2009. [suplemento]

CUNHA, E. E.; EUCLYDES, R. F.; TORRES, R. A. et al. Efeito de tipos de acasalamentos e razões sexuais na seleção baseada no BLUP. Revista Brasileira de Zootecnia, v. 32, n. 6, p. 1297-1303, 2003.

FOGEL, G. B.; PORTO, V. W.; WEEKES, D. G. et al. Discovery of RNA structural elements using evolutionary computation. Nucleic Acids Research, v. 30, n. 23, p. 5310-5317, 2002.

GONDRO, C.; KINGHORN, B.P. Application of evolutionary algorithms to solve complex problems in quantitative genetics and bioinformatics. Guelph: University of Guelph, 2008. 96 p. [apostila].

KINGHORN, B.; WERF, J.; RYAN, M. Melhoramento Animal: uso de novas tecnologias. Tradução: Vânia Cardoso e Roberto Cavalheiro. Piracicaba: FEALQ, 2006. 367 p.

LEE, S. H; . WERF, J.; KINGHONR, B. P. Using an evolucuinary algorithm and parallel computing for haplotyping in a general complex pedigree with multiple marker loci. BMC Bioinformatics, v. 189, n. 9, p. 2105-2115, 2008.

LINDEN, R. Algoritmos Genéticos: uma importante ferramenta da inteligência computacional. Rio de Janeiro: Brasport Livros e Multimídias Ltda, 2006. 348p.

MUIR, W. M. Genetic selection strategies: computer modeling. Poultry Science, v. 76, n. 8, p. 1066-1070, 1997.

NAKAMURA, E. K.; ASTOLFI, G.; RIBEIRO, J. M. G. Algoritmos genéticos. Estudos \& Pesquisa, v. 10, n. 1, p. 115-123, 2005.

NARCISO, M, G.; LORENA, L. A. N. Uso de algoritmos genéticos em sistema de apoio à decisão para alocação de recursos no campo e na cidade. Revista Brasileira de Agroinformática, $v$. 4, n. 2. p. 90-101, 2002. 
NEVES, H. H. R.; CAVALHEIRO, R.; CARDOSO, V. Acasalamento dirigido para aumentar a produção de animais geneticamente superiores e reduzir a variabilidade da progênie em bovinos. Revista Brasileira de Zootecnia, v. 38, n. 7, p. 1201-1204, 2009.

NEVES, J. P.; MIRANDA, K. L.; TORTORELLA, R. D. Progresso científico em reprodução na primeira década do século XXI. Revista Brasileira de Zootecnia. v. 39, p. 414-421, 2010 [suplemento].

PEREIRA, J. C. C. Melhoramento genético aplicado à produção animal. $5^{a}$ ed. Belo Horizonte: FEPMVZ-Editora, 2008. 617p.

QUEIROZ, S. A.; ALBUQUERQUE, L. G.; LANZONI, N. A. Efeito da endogamia sobre características de crescimento de Bovinos da raça Gir no Brasil. Revista Brasileira de Zootecnia, v. 29, n. 4, p. 1014-1119, 2000.

SATROM, P.; SNEVE, R.; KRISTIANSEN, K. I. et al. Predicting non-coding RNA genes in Escherichia Coli with boosted genetic programming. Nucleic Acids Research, v. 33, n. 10, p. 3263-3270, 2005.

SILVA, J. C. Teste de Progênie: Ferramenta de Melhoramento Genético e Avaliação / Seleção de Reprodutores Gir Leiteiro. Revista Olhar Científico, v. 1, n. 2, p. 351-368. 2010.

STORN, R.; PRICE, K. Differential Evolution - A Simple and Efficient Heuristic for Global Optimization over Continuous Spaces. Journal of Global Optimization, v. 8, n. 11, p. 341$359,1997$. 